\title{
Media Effectiveness on Commodity Purchase Behavior of University Students in Taiwan
}

\author{
Wei-Ting Huang ${ }^{1} \&$ Hsuan-Fu Ho ${ }^{1}$ \\ ${ }^{1}$ National Chiayi University, Taiwan \\ Correspondence: Hsuan-Fu Ho, National Chiyi University, 85 Wenlong Minshong, Chiayi County, Taiwan. \\ E-mail: hfho@mail.ncyu.edu.tw
}

$\begin{array}{lc}\text { Received: October 6, } 2014 & \text { Accepted: November 30, } 2014 \quad \text { Online Published: January 14, } 2015 \\ \text { doi:10.5539/ass.v11n4p378 } & \text { URL: http://dx.doi.org/10.5539/ass.v11n4p378 }\end{array}$

\begin{abstract}
The accelerating progress of the communication technologies in the past two decades has made media advertisement an inevitable marketing strategy for business success. Individuals in contemporary society receive more information than ever, and their attention is dispersed over more forms of media. Therefore, an understanding of the strengths and weaknesses of different media is crucial for businesses to survive the fiercely competitive new market. This study thus endeavored to investigate how frequently university students expose to different media? Message conveyed by what media are more persuasive? How students' socio-demographic backgrounds might influence their media use patterns? A self-developed questionnaire was administered to 250 university students in Taiwan. The results indicated that internet was appraised as the most adequate media for advertising to university students in terms of exposure frequency and message persuasion.
\end{abstract}

Keywords: advertisement, media, higher education, student, persuasion, exposure

\section{Introduction}

Due to the great advancement of communication technologies, modern people live in an audiovisual environment. Therefore, individuals in contemporary society receive more information than ever, and they use communication media, such as newspaper, radio, television and so on to collect data and information they need (Hamilton, Richards, \& Stiegert, 2013). These technology inventions have thoroughly prevailed among our lives, indicating that today's information is disseminated to a broader audience, and at the same time, audiences are exposed to a wider range of media messages.

"Media" refer to the dissemination of information and serve as the bridge between communicators and recipient. The media have now become a general term for various communication tools, such as the internet, television, radio, magazines and newspapers. Nowadays, business leaders have made use of media to advertise their products. However, advertisement has been observed from different viewpoints, and media effects vary a great deal among different social groups (Guillaumier, Bonevski, \& Paul, 2012), and therefor, it is crucial to have a good understanding of the characteristics of different media. Establishing criteria for media selection is thus vital for making good decisions. Among the criteria commonly adopted by business leaders, message persuasiveness (Heehs, 2006) and exposure frequency definitely are important factors that should be considered (Oyekunle \& Tiamiyu, 2010; Nettelhorst, \& Youmans, 2012).

On the other hand, since the amount of information extending for the customers today is much more than it was a couple of years ago, a well recognition of the characteristics of different media is not only important for business leaders to enhance their advertising results, but also critical for students to gain the information more smoothly and efficiently.

Given the aforementioned importance of media usage by college students, much research has not yet been done enough in this area. We thus endeavored to investigate how frequently university students expose to different media, and messages conveyed by what media were perceived by students as more persuasive. We manipulated six media types (television, radio, Internet, magazine, newspaper and outdoor advertising) to examine the media using frequency of students. In addition, previous research has shown that different sorts of media may create different outlooks toward advertisements, and therefore, these six media were once again been used to examine the media persuasiveness. 


\section{Literature Review}

\subsection{Defining Mass Media}

Mass media have long been a popular topic among social scientists because it possess strong economic, political and educational power over the general public. Entering the knowledge-economy era, the society is increasingly driven by enormous amount of information, and realizing the characteristics of the media is thus of great importance. Given the aforementioned promminence of mass media, there is still no consensus among scholars on the exact defintion of mass media.

Piotrowski (2013) defined mass media as the technological tools which spread information to a lot of anonymous receivers. Mark (2007) whereas viewed media as numerous patterns of mass communication channels which include television, radio, magazines, newspapers and sometimes involving people. Guillaumier, Bonevski, and Paul (2012) claim a very similar definition to Mark's, and he suggests that "media" refers to communication means, which can be used to communicate and interact among people. Newspaper, television, radio, magazine, internet, and outdoor advertisements (billboard, flyers, and posters) are the most commonly used media. Kling, Hoffman, and Novak (1997) further argue that the traditional defintion of mass media is based on a one-to-many information transfering proess, and business diseminatte its message through a medium or a set of media mix to a large group of consumers. Now-a-days, however, the marketing environment has dramatically changed by the Word Wide Web system, and mass media should currently be defined as a set of many-to-many communication channels.

\subsection{Functions of Mass Media}

The acceleration of technology in the $21^{\text {st }}$ century has forced people in the world to expose themselves to more media than ever. As a result, media have become the most important instruments for the businesses to sell their products, and develop a media mix for reaching a larger audience with less costs is one of the most crucial tasks for business success. However, since different media has different effects to different people, it is of great importance for enterprises to recognize the characteristics of each medium, and at the same time, to understand how consumers use the various media for information collection. (Chang, Wu, Tseng, Su, \& Ko, 2012).

In addition to the application of media for business marketing purposes, media also widely used for promoting social benefits and for gaining supports for government policies. Since media impact the observations of the young toward society, they become the best instrument for the government to form cultural regulations among different social groups, and they often are used for policy education and for political campaigns (Rooban, Kumar, \& Ranganathan, 2010; Gollust, Lantz, \& Ubel, 2009; Kemp, Eagle, \& Verne, 2011).

Finally, viewing from the customer's stands, mass media are both a good entertainment and an inevitable instrument for their daily life. Since media bring more chances to improve the quality of life for individuals, and since it has played a vital role on disseminating latest information to individuals, it is essential for modern people to possess in-depth understanding about the media (Mirza, 2005; Iasmina, Tiberiu, Mihaela, Diana, \& Gabriela, 2013; McDaniel, Naphtali, Yerger, \& Malone, 2014).

\subsection{Strengthes and Weaknesses of Different Media Advertisements}

As for advertising, Biddle (2014) elaborated that media are crucial instrument for communication and message transporting apparutus, which allow buisness leaders to gather and disseminate product messages speedily and effectively. However, people not just devote their time to a single medium, indicating that consumers' attention is dispersed over more types of media (Franz, 2000), and therefore, an in-depth understanding of the related strengths and weaknesses of different media will help enterprises to improve their using of media (Macias, Pashupati, \& Lewis, 2007).

Since almost all companies have restricted money for advertsiement, economic efficiency or cost minimization often perceived as the most crucial consideration when developing an industry's media mix (Färe, Grosskopf, Seldon, \& Tremblay, 2004). However, since the attempts of using media is to attract more customers, the profit-maximizing manner is eqully important, and criteria such as exposure frequency and message persuasion should be under serious attention (Franz \& Ridout, 2007; Chang, Wu, Tseng, Su, \& Ko, 2012; Rooban, Kumar, $\&$ Ranganathan, 2010). The strengthes and weaknesses are summarized as follows:

Newspaper is more wide-reaching and includes more pictures than many other print media (Iasmina, Tiberiu, Mihaela, Diana, \& Gabriela, 2013). Moreover, newspaper often reports or describes a message more thoroughly, and since readers can read them at any time, they are more informative than television (Macias, Pashupati, \& Lewis, 2007). Nevertheless, Mark (2007), McDonald and Johnson, 2013, and Biddle (2014) all argue that although newspapers are potential transporting devices for all categories of advertising information, and are thus 
widely used by a wide range of institutions for message dissemination, newspapers have gradually lost the popularity because of the competition from the internet.

Radio advertisements are less expensive, and they are as wide-reaching as television and newspaper; therefore, in many lower and middle income countries, radio advertisement has more audiences than television (Durkin \& Wakefield, 2009). One of the biggest problems of radio advertisement is that listeners often switch to other radio station when advertisment airs, and therefore, enterprises only have the first few seconds to attract and catch listeners' interests.

In addition to reaching great number of audiences, television also offers images and sound by utilizing special effects and drama to create colorful views, and therefore, television commercials are often more attractive to audiences (Iasmina, Tiberiu, Mihaela, Diana, \& Gabriela, 2013). However, since television commercials tend to be professionally produced, they cost relatively much more than radio advertisements and newspaper advertisements. Moreover, the costs for buying the air time will also cost the industries a fortune. As a result, the television commercials tend to be very short, which in turn restricts time available for audiences to retrieve ideas and messages. Furthermore, it is also unpreventable if audiences will skip the advertisements to another channels (Macias, Pashupati, \& Lewis, 2007).

In spite of other kinds of media, purchasers have taken advantage of the radical growth and improvement in the amount of magazines in recent decades. Magazines advertisements have relative long duration and reading cirulation, and it reaches readers with specific interests. The main weaknesses of magazine advertisments are the comparatively narrower exposure, and the unpredictable advertisement responses schedule, given that magazines are not always being read immediately after its publication. Moreover, it often costs much more to produce a magazine advertisement than other print media (Chattopadhyay, Dutta, \& Sivani, 2010; Chang, Wu, Tseng, Su, \& Ko, 2012).

Outdoor advertisements enjoy the benefits of being seen repeatedly by people taking the same route or sitting in the same place, and therefore, is a good medium to match the geographical location of the target audiences. Moreover, the outdoor advertisements will also reach captive audiences who are not likely to tune out easily.

However, since outdoor advertisements only catch the attention of audiences for a very short period, the messages must be extremely brief. Moreover, outdoor advertisements are easily to be vandalized by weather or other environmental threats.

Internet media can effectively convey messages in different forms (texts, pictures, video, audio) to their target costomers with less costs than the traditional markting media. Internet marketing often enjoy the benefit of deeper interactions with the consumers, which in turn building a stronger relationship between organization and individuals. Moreover, internet media not only able to reach a wide variety of audiences, they often have the benefit of enpowering the audience, through a "collaboration" with the consumers to further disemminate the product messages to other audiences (Subramaniam, Shaw, \& Gardner, 2000). However, risk of damaging customer's privacy and skeptical security issues are often discussed as the weaknesses of internet advertisements. Moreover, false information are also easily been spread through internet (Kalyanam \& McIntyre, 2002; Cheng, 2009; Weinberg \& Pehlivan, 2011).

\section{Methodology}

\subsection{Research Framework}

This research is endeavored to explore the media usage pattern of university students in Taiwan. As shown in Figure 1. We tried to investigate the exposure frequency and persuasiveness of different media among university students, to determine the strengths and weaknesses of different media on promoting a variety of purchasing items, and to examine the variety of media usage patterns among students with different backgrounds.

\subsection{Development of Research Instrument}

This research is aimed to understand the media exposure frequency and message persuasiveness perceived by college students. A self-developed questionnaire entitled "Media Exposure Frequency and Message Persuasiveness on Purchase Behavior of University Students" was adopted as the main instrument for data collection. The questionnaire was comprised of three parts, the first part was mainly used to elicit demographic information of the participants, and the second part was devoted to explore the purchase behavior of university students. The third part contains 36 Likert's four-point scale questions to survey the exposure frequency of different media on university students, where $1=$ never and $4=$ always. Finally, the fourth part was composed of another 36 Likert's four-point scale questions to understand the persuasiveness of messages carried by different media on students' purchase behaviors, where $1=$ not persuasive and $4=$ very persuasive. 


\subsection{Validity and Reliability}

To ensure the questionnaire's content validity, 5 scholars were invited to review the questionnaire, and only minor adjustments were suggested and were made to improve the clarity and appropriateness of the questions. Thereafter, chronbach's $\alpha$ were adopted for examining the reliability, and with chronbach's $\alpha$ equals to .739 for the third part (exposure frequency) and .943 for the fourth part (message persuasiveness), indicating that this questionnaire has high reliability.

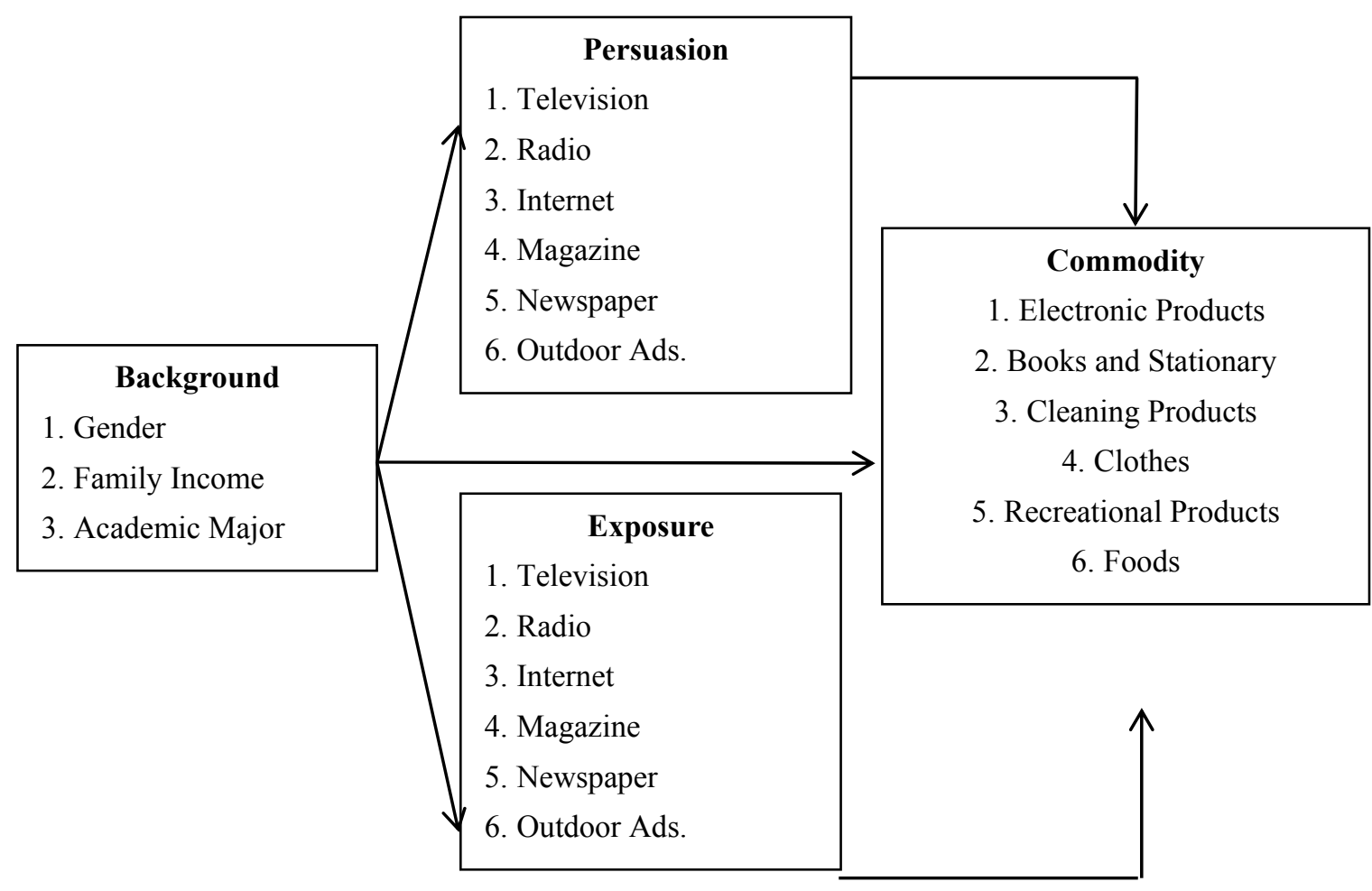

Figure 1. Research framework

\subsection{Sampling and Schedule}

The final edition of the questionnaire was then administered to 250 university students in Taiwan, of which, 223 were retrieved, resulting in a returning rate of $89.2 \%$. The sample included students from a wide range of academic areas, and the sample distribution is similar to that of the population. The research was conducted from April 2014 to July 2014.

\section{Research Results}

\subsection{Where Did Students' Money Goes}

We first tried to understand where did student's money goes? The research results indicated that students spent more than half of their money on food (53\%), and the rest of their money were almost equally distributed to the other items. This was the result of the truth that students often in a restricted economic condition, and since they do not have much money for free use, they need to weigh and balance every penny. Since food is an inevitable necessity, students expended largely on food while cutting down their expenses on other products that were not as crucial. 


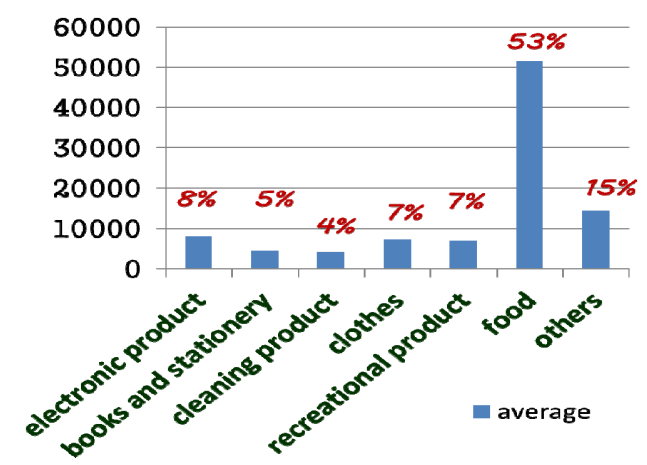

Figure 2. Expenditure pattern of university students

\subsection{Exposure Frequency}

University students in Taiwan relied heavily on internet to collect information of the living goods. Students rated the internet as the most frequently used media when collecting information about electronic products, books and stationary, cleaning products, clothes, recreational products, and food. Moreover, TV commercial were also used very often for transferring products messages to students for almost all kind of commodities. Magazine is another good medium to convey messages to students, especially in selling books, stationary, and clothes. Finally, outdoor advertisement is a good medium for transferring messages of food to students.

Table 1. Exposure frequency of media on products

\begin{tabular}{lllllll}
\hline & TV & Radio & Internet & Magazine & Newspaper & Outdoor Ads. \\
\hline Electronic Products & 2.21 & 1.26 & 3.23 & 2.01 & 1.72 & 1.87 \\
Books and Stationary & 1.72 & 1.24 & 2.95 & 2.05 & 1.56 & 1.82 \\
Cleaning Products & 2.43 & 1.23 & 2.72 & 2.05 & 1.60 & 1.89 \\
Clothes & 1.98 & 1.22 & 3.22 & 2.34 & 1.61 & 1.89 \\
Recreational Products & 2.42 & 1.30 & 3.07 & 2.08 & 1.79 & 1.93 \\
Food & 2.68 & 1.34 & 3.05 & 2.19 & 1.98 & 2.19 \\
\hline
\end{tabular}

\subsection{Message Persuasiveness}

Exposure frequency by itself cannot ensure the effectiveness of a media because message receivers may ignore or doubt the information it conveyed even when they were exposed to that media very often. Therefore, it is equally important to consider the message persuasiveness conveyed by different media if the aim is to enhance the effectiveness of an industry's promotional strategy. The fourth part of the questionnaire was thus devoted to measure the persuasiveness of the messages conveyed by different media on students' purchase behaviors. The results showed that Internet, once again, was rated as the most persuasive medium for all kinds of commodities. Moreover, the messages conveyed by television were also persuasive, especially in selling electronic products, cleaning products, recreational products, and food to students. Finally, messages conveyed by magazine were also effective in selling books, stationary, and clothes.

Table 2. Persuasiveness of media on products

\begin{tabular}{lllllll}
\hline & TV & Radio & Internet & Magazine & Newspaper & Outdoor Ads. \\
\hline Electronic Products & 2.54 & 1.41 & 2.97 & 2.38 & 2.00 & 1.97 \\
Books and Stationary & 2.09 & 1.45 & 2.89 & 2.32 & 1.92 & 1.96 \\
Cleaning Products & 2.55 & 1.42 & 2.78 & 2.44 & 1.91 & 1.96 \\
Clothes & 2.30 & 1.37 & 2.99 & 2.52 & 1.91 & 2.00 \\
Recreational Products & 2.53 & 1.45 & 3.00 & 2.42 & 2.05 & 2.06 \\
Food & 2.76 & 1.47 & 3.00 & 2.49 & 2.18 & 2.14 \\
\hline
\end{tabular}




\subsection{Background Effects}

It is also important to understand how student's background variables might affect their media using patterns. We first examined how male students might differ from their female counterparts in media usage on commodity purchase, and the research results indicated that female students used the media of radio, the internet, magazine, and outdoor advertisement more frequently than their male counterparts. However, as for the message persuasiveness, only outdoor advertisement revealed a significant difference between female and male students.

Finally, several one-way ANOVA were conducted to exmine whether students' family household income and students' academic major significantly affect their rating on media exposure frequency and message persuasiveness, and the results indicated that there existed no significant differences.

Table 3. T-test of gender to frequency and persuasiveness

\begin{tabular}{|c|c|c|c|c|c|c|c|}
\hline \multirow{2}{*}{ Media } & \multirow{2}{*}{ Gender } & \multicolumn{3}{|c|}{ Frequency } & \multicolumn{3}{|c|}{ Persuasiveness } \\
\hline & & Mean & $\mathrm{t}$ & sig & Mean & $\mathrm{t}$ & sig \\
\hline \multirow{2}{*}{ TV } & male & 2.004 & \multirow{2}{*}{.838} & \multirow{2}{*}{.403} & 2.205 & \multirow{2}{*}{.029} & \multirow{2}{*}{.977} \\
\hline & female & 2.066 & & & 2.202 & & \\
\hline \multirow{2}{*}{ Radio } & male & 1.798 & \multirow{2}{*}{2.28} & \multirow{2}{*}{.024} & 2.064 & \multirow{2}{*}{.830} & \multirow{2}{*}{.407} \\
\hline & female & 1.955 & & & 2.124 & & \\
\hline \multirow{2}{*}{ Internet } & male & 1.830 & \multirow{2}{*}{3.09} & \multirow{2}{*}{.002} & 2.117 & \multirow{2}{*}{1.12} & \multirow{2}{*}{.266} \\
\hline & female & 2.083 & & & 2.208 & & \\
\hline \multirow{2}{*}{ Magazine } & male & 2.158 & \multirow{2}{*}{2.75} & \multirow{2}{*}{.007} & 2.428 & \multirow{2}{*}{.950} & \multirow{2}{*}{.344} \\
\hline & female & 2.405 & & & 2.514 & & \\
\hline \multirow{2}{*}{ Newspaper } & male & 2.029 & \multirow{2}{*}{1.3} & \multirow{2}{*}{.195} & 2.209 & \multirow{2}{*}{.694} & \multirow{2}{*}{.488} \\
\hline & female & 2.135 & & & 2.264 & & \\
\hline \multirow{2}{*}{ Outdoor Ads. } & male & 2.093 & \multirow{2}{*}{2.77} & \multirow{2}{*}{.006} & 2.225 & \multirow{2}{*}{2.05} & \multirow{2}{*}{.041} \\
\hline & female & 2.334 & & & 2.394 & & \\
\hline
\end{tabular}

\section{Conclusions}

The accelerating progress in communicational technologies has made media advertsiment an inevitable marketing instrument for business success. Understanding the characteristics of different media is crucial not only for business to enhance their selling results, but also essential for students to collect the product's information efficiently. This research is thus aimed to examine the exposure frequency and message persuasiveness of the six major media on commodities that commonly purchased by university students.

The results showed that the internet beat television, radio, newspaper, magazine, and outdoor advertisements as the most frequently exposed media, and the message conveyed by internet was also rated by students as more persuasive than messages conveyed by all the other media. Hence, it is crucial for business to understand more of the on-line advertisements if their aim is to enhance their marketing results.

Moreover, although newspaper and radio had been the most important mass media for advertisement in the past years, they are no-longer popular in this internet era, and this trend is especially true among university students because now-a-days young people spend a great deal of their time on-line, and since the internet provides them with an efficient, convenient and comfortable way of information searching, they do not have to rely on newspaper and radio anymore. Therefore, industries and advertisers should be extremely careful if they intend to adopt these two types of media as their major promotional instruments.

The research results also indicated that female students exposed themselves to the commercials carried by internet, radio, magazine, and outdoor advertisement much more frequent than their male counterparts. For this reason, industries producing female commodities may adopt the aforementioned media for their products promotion.

Finally, although this study provides insights for the media usage patterns on purchase behaviors of university students, the reasons behind these behavior patterns were not explored. Therefore, qualitative approaches may be conducted in the future to further advance the effectiveness of media commercials. Moreover, this study focused specifically on university students, and therefore the findings should not be generalized to other social groups. 
Future research might thus investiage whether the pattern revealed in this study also applicable to other groups.

\section{References}

Biddle, I. (2014). The print media industry: A model under change. BusiDate, 22(2), 2-4.

Botha, E., \& Reyneke, M. (2013). To share or not to share: The role of content and emotion in viral marketing. Journal of Public Affairs, 13(2), 160-171. http://dx.doi.org/10.1002/pa.1471

Chang, S., Wu, T., Tseng, H., Su, Y., \& Ko, C. (2012). Media mix decision support for schools based on analytic network process. International Journal of Industrial Engineering, 19(7), 297-304.

Chattopadhyay, T., Dutta, R. N., \& Sivani, S. (2010). Media mix elements affecting brand equity: A study of the Indian passenger car market. IIMB Management Review, 22, 173-185. http://dx.doi.org/10.1016/j.iimb. 2010.09.001

Cheng, C. T. (2009). New media and event: A case study on the power of the internet. Knowledge, Technology, and Policy, 22, 145-153. http://dx.doi.org/10.1007/s12130-009-9078-8

Durkin, S., \& Wakefield, M. (2009). Comparative responses to radio and television anti-smoking advertisements to encourage smoking cessation. Health Promotion International, 25(1), 5-13. http://dx.doi.org/10.1093/ heapro/dap044

Färe, R., Grosskopf, S., Seldon, B. J., \& Tremblay, V. J. (2004). Advertising efficiency and the choice of media mix: A case of beer. International Journal $f$ Industrial Orgnaization, 22, 503-522. http://dx.doi.org/10. 1016/j.ijindorg.2 003.10.002

Franz, M. M., \& Ridout, T. N. (2007). Does political advertising persuade? Political Behavior, 29, 465-491. http://dx.doi.org/10.1007/s11109-007-9032-y

Guillaumier, A., Bonevski, B., \& Paul, C. (2012). Anti-tobacco mass media and socially disadvantaged groups: A ysstematic and methodological review. Drug and Alcohol Review, 31, 698-708. http://dx.doi.org/10.1111 /j.1465-3362.2012.00466.x

Gullust, S. E., Lantz, P. M., \& Ubel, P. A. (2009). The polarizing effect of new media messages about the social determinants of health. American Journal of Public Health, 99(12), 2160-2167. http://dx.doi.org/10.2105/ AJPH.2009.161414

Hamilton, S. F., Richards, T. J., \& Stiegert, K. W. (2013). How does advertising affect market performance? A note on generic advertising. Economic Inquiry, 51(2), 1183-1195. http://dx.doi.org/10.1111/j.1465-7295. 2011.00405.x

Heehs, P. (2006). Introduction: A ropriation as a marketing strategy. Postcolonial Studies, 9(2), 113-119. http://dx.doi.org/10.1080/13688790600664179

Iasmina, I., Tiberiu, I., Mihaela, I., Diana, M., \& Gabriela, P. (2013). Mass-media and communication terminology. Agronomy Series of Scientific Research, 56(2), 319-321.

Kalyanam, K., \& McIntyre, S. (2002). The e-marketing mix: A contribution of the e-tailing wars. Journal of the Academy of Marketing Science, 30(4), 487-499. http://dx.doi.org/10.1177/009207002236924

Kemp, G. A., Eagle, L., \& Verne, J. (2011). Mass media barriers to social marketing interventions: The example of sun protection in the UK. Health Promotion International, 26(1), 37-45. http://dx.doi.org/10.1093/ heapro/daq048

Kling, R., Huffman, D. L., \& Novak, T. P. (1997). A new marketing paradigm for electronic commerce. Information Society, 13(1), 43-54. http://dx.doi.org/10.1080/019722497129278

Macias, W., Pashupati, K., \& Lewis, L. S. (2007). A wonderful life or diarrhea and dry mouth? Policy issues of direct-to-consumer drug advertising on television. Health communication, 22(3), 241-252. http://dx.doi.org/ $10.1080 / 10410230701626893$

Mark, D. (2007). Try a Fresh Perspective on Media. Television Week, 26(41), 22-22.

McDaniel, P. A., Naphtali, O., Yerger, V. B., \& Malone, R. E. (2014). A breath of fresh air worth spreading: Media coverage of retailer abandonment of tobacco sales. American Journal of Public Health, 104(3), 562-569. http://dx.doi.org/10.2105/AJPH.2013.301564

McDonald, D. G., \& Johnson, B. K. (2013). Is time money? Media expenditure in economic and technological turbulence. Journal of Broadcasting and Electronic Media, 57(3), 282-299. http://dx.doi.org/10.1080/0883 


\subsection{3 .816705}

Nettelhorst, S., \& Youmans, R. J. (2012). The effects of advertisement variation and need for cognition on attitudes toward products. The New School Psychology Bulletin, 9(2), 68-73.

Oyekunle, R. A., \& Tiamiyu, M. A. (2010). Patterns of information products advertising in newspaper media in Nigeria. African journal of Library, Archives, and Information Science, 20(2), 71-81.

Piotrowski, M. (2013). Mass media and rural out-migration in the context of social change: Evidence from Nepal. International Migration, 51(3), 169-193. http://dx.doi.org/10.1111/j.1468-2435.2010.00627.x

Rabbi, A. M. F. (2012). Mass media exposure and its impact on fertility: Current scenario of Bangladesh. Journal of Scientific Research, 4(2), 383-395.

Ritter, E. A. (2009). Effects of ad placement and type on consumer responses to podcast ads. Cyber Psychology \& Behavior, 12(5), 533-537. http://dx.doi.org/10.1089/cpb.2009.0074

Rooban, T., Kumar, P. D. M., \& Ranganathan, K. (2010). Reach of mass media among tobacco users in India: A preliminary report. Indian Journal of Cancer, 47(1), S53-S58. http://dx.doi.org/10.4103/0019-509X.63869

Segovia, J. B. (2013). Masking as a persuasive strategy in advertising for young. Scientific Journal of Media Education, 21(41), 157-165.

Subramaniam, C., Shaw, M. J., \& Gardner, D. M. (2000). Product marketing and channel management in electronic commerce. Information Systems Frontiers, 1(4), 363-378. http://dx.doi.org/10.1023/A:10100 61924822

Weinberg, B. D., \& Pehlivan, E. (2011). Social spending: Managing the social media mix. Business Horizons, 54(3), 275-282. http://dx.doi.org/10.1016/j.bushor.2011.01.008

\section{Copyrights}

Copyright for this article is retained by the author(s), with first publication rights granted to the journal.

This is an open-access article distributed under the terms and conditions of the Creative Commons Attribution license (http://creativecommons.org/licenses/by/3.0/). 